\title{
The ACAA-insertion/deletion polymorphism at the 3' UTR of the IGF-II receptor gene is associated with type 2 diabetes and surrogate markers of insulin resistance
}

\author{
Gemma Villuendas $^{1}$, José I Botella-Carretero ${ }^{1}$, Abel López-Bermejo ${ }^{3}$, Carme Gubern ${ }^{3}$, Wifredo Ricart ${ }^{3}$, \\ José Manuel Fernández-Real ${ }^{3}$, José L San Millán ${ }^{2}$ and Héctor F Escobar-Morreale ${ }^{1}$ \\ Departments of ${ }^{1}$ Endocrinology and ${ }^{2}$ Molecular Genetics, Hospital Universitario Ramón y Cajal and Universidad de Alcalá, Carretera de Colmenar Km. 9.1, \\ Madrid E-28034, Spain, and ${ }^{3}$ Section of Diabetes, Endocrinology and Nutrition, Hospital Universitario Dr Josep Trueta, E-17007 Girona, Spain \\ (Correspondence should be addressed to H F Escobar-Morreale; Email: hescobarm.hrc@salud.madrid.org)
}

\begin{abstract}
Objective: The IGF-II receptor gene (IGFIIR) is located at chromosome 6q26, a region that harbors a genetic marker linked to insulin-resistant traits in Mexican-Americans. In the present study conducted in Spaniards, we tested a common polymorphism in IGFIIR for association with type 2 diabetes and insulin-resistant traits.

Design: Case-control association study.

Methods: One hundred and forty-five type 2 diabetic patients and 217 non-diabetic controls were genotyped for the ACAA-insertion/deletion polymorphism at the $3^{\prime}$ UTR of IGFIIR. Phenotyping included anthropometrics and a metabolic profile, including serum lipid levels and surrogate indexes of insulin resistance whenever possible.

Results: Diabetic patients were more frequently homozygous for the wild type $144 \mathrm{bp}$ allele of IGFIIR compared with controls (diabetic patients $77.2 \%$, controls $51.6 \%, P<0.001$ ) suggesting a potential protective role against type 2 diabetes for the IGFIIR $140 \mathrm{bp}$ variant. Carrying $140 \mathrm{bp}$ alleles was associated with an odds ratio of having diabetes of 0.290 (95\% confidence interval $0.109-0.770)$, and controls homozygous for the wild type $144 \mathrm{bp}$ allele presented with lower insulin and triglyceride levels, which are proxies for insulin resistance.

Conclusions: The ACAA-insertion/deletion polymorphism at the $3^{\prime}$ UTR of IGFIIR is associated with type 2 diabetes and influences surrogate markers of insulin resistance in non-diabetic subjects.
\end{abstract}

European Journal of Endocrinology 155 331-336

\section{Introduction}

The insulin-like growth factor (IGF) system is a candidate to participate in the genetic background of type 2 diabetes (1). On the one hand, low plasma IGF-I levels have been associated with an increased risk to develop type 2 diabetes in humans (2). IGF-I mainly acts via the IGF-I receptor, which has structural homology with the insulin receptor, and upon its activation is capable of increasing cell numbers by inhibiting apoptosis in several tissues (3). In conceptual agreement, an IGF-I gene polymorphism influences insulin sensitivity (4), and IGF-I receptor gene variants have also been hypothesized to play a role in the pathogenesis of type 2 diabetes (5).

On the other hand, overexpression of IGF-II in pancreatic $\beta$ cells in transgenic mice models is followed by development of type 2 diabetes, fatty liver and obesity, despite an increase in $\beta$ cell mass (6). The role of IGF-II in the development of $\beta$ cells is further supported by the finding that impaired IGF-II production during fetal development may result into retardation of $\beta$ cell growth in a rat model of type 2 diabetes (7). Supporting a role of IGF-II in the development of insulin-resistant disorders in humans, IGF-II gene polymorphisms have been found in association with increased body mass index (BMI) in adult males (8), and with the polycystic ovary syndrome in Caucasian premenopausal women (9).

The IGF-II receptor is a multifunctional glycoprotein that has been proposed to influence tumor suppression and immunity $(10,11)$. The IGF-II receptor gene (IGFIIR) is located at chromosome 6q (12). Although in rodents, IGFIIR is imprinted and only maternally inherited alleles are expressed, in humans repressed expression of paternal IGFIIR alleles is only present in a small subset of subjects (13). Considering that the $6 \mathrm{q}$ region has shown evidence for linkage with insulin resistance and obesity-related metabolic phenotypes (14), we hypothesized that IGFIIR could be a positional candidate gene for type 2 diabetes. 
This suspicion was further highlighted by our previous unpublished data suggesting an unexpected association of the ACAA-insertion/deletion polymorphism in the $3^{\prime}$ UTR of IGFIIR with obesity and insulin resistance in hyperandrogenic women, although we were not able to demonstrate an association of this polymorphism with polycystic ovary syndrome (9), which was the actual aim of the study. Together with the association of the $6 \mathrm{q}$ region with insulin resistance and obesity-related metabolic phenotypes described above (14), our findings in hyperandrogenic women prompted us to evaluate the possible association of the ACAA-insertion/deletion polymorphism in the $3^{\prime}$ UTR of IGFIIR with insulin resistance and type 2 diabetes in Caucasian individuals from Spain using a case-control approach.

\section{Subjects and methods}

\section{Subjects}

Three hundred and sixty-two Caucasian subjects recruited for an ongoing study addressing non-classical cardiovascular risk factors, were included in the present study. Two hundred and seventeen non-diabetic controls were selected on the basis of fasting plasma glucose $<6.1 \mathrm{mmol} / \mathrm{l}$ and BMI $<40 \mathrm{~kg} / \mathrm{m}^{2}$. Control subjects were neither receiving pharmacological treatment or had any evidence of metabolic disease other than overweight or non-morbid obesity. One hundred and forty-five patients with type 2 diabetes, defined according to the criteria of the American Diabetes Association (15), were prospectively recruited from diabetes outpatient clinics. Only patients who presented with a stable metabolic control within the previous 6 months, as defined by HbAlc values, were recruited. Pharmacological therapies for these patients included insulin $(44.8 \%)$, oral hypoglycemic agents $(72.9 \%)$, statins $(38.0 \%)$, fibrates $(10.6 \%)$, blood pressure lowering agents $(61.5 \%)$, aspirin $(42.7 \%)$ and allopurinol $(4.2 \%)$.

For both diabetic patients and controls, exclusion criteria included: (i) clinically significant hepatic, neurological, endocrine or other major systemic disease, including malignancy, (ii) hemochromatosis, (iii) drug or alcohol abuse, defined as alcohol intake $>80 \mathrm{~g} /$ day in men and $>40 \mathrm{~g} /$ day in women, or serum transaminase activity more than twice the upper limit of normal, (iv) elevated serum creatinine concentration, (v) occurrence of an acute major cardiovascular event in the previous 6 months, (vi) acute illnesses and current evidence of acute or chronic inflammatory or infective diseases and (vii) mental illness rendering the subjects unable to understand the nature, scope and possible consequences of the study. All the subjects gave written informed consent and the Institutional Review
Boards of the participating hospitals approved the protocol.

\section{Methods}

Anthropometric variables and clinical blood pressure were measured. A complete metabolic profile, including fasting glucose and insulin levels and serum lipid concentrations, was performed whenever possible as previously described (16). DNA was extracted from lymphocytes by the salting-out method. Genotyping of the ACAA-insertion/deletion polymorphism at the $3^{\prime}$ UTR of IGFIIR (GenBank sequence NT-007422, NCBI SNPs Data Base: rs8191962), which results in alleles sized 140 or $144 \mathrm{bp}$, were performed by PCR using fluorescent dye-labeled forward primers, followed by use of an ABI310 Automated Sequencer (Applied Biosystems, Foster City, CA, USA). Primer sequences and allele sizes were described previously (17). The accuracy of genotyping was evaluated by retesting one of each of the eight samples, selected in a blinded manner, on different days. The identity of the PCR product was verified by direct sequencing of ten samples, representing the three genotypes, amplified with non-fluorescent primers.

\section{Statistical analysis}

A priori power analysis of the differences in allele frequencies between type 2 diabetic patients and controls was performed by PASS2000 software (Number Cruncher Statistical Systems, Kaysville, UT, USA). For a 0.80 power with $0.05 \alpha$, the $\chi^{2}$ test with 1 degree of freedom allowed the detection of an effect size for the difference between frequencies $(w)$ of 0.15 by including a sample size of 350 individuals. To take into account the case to control ratio, power analysis using the $\chi^{2}$ test for two group proportions was also performed (18). Our previous data indicated a 55\% prevalence of IGFIIR 140 carriers among healthy control women (9). Taking the latter data and for a 0.80 power with $0.05 \alpha$, in order to detect a 0.15 difference in frequencies between type 2 diabetic patients and controls, and for a patient/control ratio of $1 / 1.5$, sample sizes should be at least of 125 and 185 individuals respectively. Of note, effect sizes between 0.10 and 0.30 are considered small by convention (19). Results are expressed as mean \pm s.D. unless otherwise stated. The Kolmogorov-Smirnov statistic was applied to continuous variables. Logarithmic transformation was applied as needed to ensure normal distribution of the variables. Unpaired $t$-tests were used to compare the central tendencies of the different groups. Analysis of covariance using the univariate general linear model (GLM) tool was performed to correct for the effect of age between patients and controls. To evaluate the association between discontinuous variables, we used the $\chi^{2}$ test and 
Fisher's exact test as appropriate. The deviation from Hardy-Weinberg equilibrium was also evaluated by the $\chi^{2}$ test.

The influence of the different genotypes on clinical and biochemical variables was analyzed by unpaired $t$-tests. Multivariate logistic regression was performed to evaluate the impact of the IGFRII genotype and other risk factors on the presence of type 2 diabetes in our series. A backwards stepwise introduction of independent variables with a probability of $F$ to enter $<0.05$ and a probability of $F$ to remove $>0.1$ was employed. Analyses were performed using SPSS 10 for the Macintosh (SPSS Inc, Chicago, IL, USA). $P<0.05$ was considered statistically significant.

\section{Results}

The clinical and biochemical characteristics of diabetic patients and controls are summarized in Table 1 . Gender was equally distributed in both groups, yet diabetic patients were older than controls and, therefore, age was included as a covariant in the univariate GLM analyses. As expected from the usual association between type 2 diabetes and other components of metabolic syndrome, BMI, systolic and diastolic blood pressure, and serum levels of triglycerides were higher, whereas serum high-density lipoprotein (HDL)-cholesterol levels were lower, in diabetic patients when compared with controls, even after correcting for the difference in age. However, serum low-density lipoprotein (LDL)-cholesterol levels were lower in diabetic patients, probably reflecting the significant number of these patients, who were receiving pharmacological treatment. As expected, waist to hip ratio and fasting glucose and insulin levels were higher in diabetic patients compared with controls. The IGFIIR genotypes and allele frequencies were in Hardy-Weinberg equilibrium (Table 2).

Diabetic patients were more frequently homozygous for wild-type (144 bp) alleles of IGFIIR compared with controls $(P<0.001)$ suggesting a potential protective role against type 2 diabetes for the IGFIIR $140 \mathrm{bp}$ variant (Table 2). We also analyzed the distribution of IGFIIR genotypes distribution between patients and controls after stratifying the population by gender. This analysis confirmed those obtained by analyzing women and men as a whole, suggesting that gender did not affect the prevalence of IGFIIR genotypes in controls and diabetic patients (Table 2). To evaluate the relative contribution of known associated factors with type 2 diabetes and the IGFIIR genotypes studied here on diabetic status, we performed multivariate logistic regression with a backward stepwise method in which having type 2 diabetes was introduced as the dependent variable, and age, gender, circulating LDL-cholesterol, HDL-cholesterol and triglycerides, BMI and ACAAinsertion/deletion IGFIIR genotypes were introduced as independent variables. Patients on statins and/or fibrates were excluded from this analysis.

The model retained carrier status for $140 \mathrm{bp}$ alleles of the IGFIIR ACAA-insertion/deletion polymorphism (odds ratio 0.290 (95\% confidence interval (CI) 0.109-0.770)), age (odds ratio 1.117 (95\% CI 1.0741.161)), BMI (odds ratio 1.141 (95\% CI 1.037-1.256)) triglycerides levels (odds ratio 1.015 (95\% CI 1.0091.021)) and male gender (odds ratio 5.167 (95\% CI 1.674-15.956)) as statistically significant predictors of type 2 diabetes in our model $\left(\chi^{2}=133.024, P<0.001\right.$, Nagelkerke's $R^{2}=0.637$ ), further suggesting a potential protective role of the IGFIIR 140 bp variant against the development of type 2 diabetes. Finally, we studied the influence of IGFIIR ACAA-insertion/deletion genotypes on the phenotype of the subjects studied here. Yet considering that the phenotype of diabetic patients was interfered by diabetes itself and by the treatment received by these individuals, these analyses were restricted to the non-diabetic controls. Controls carrying $140 \mathrm{bp}$ alleles of the IGFIIR ACAA-insertion/deletion polymorphism presented with lower fasting insulin and serum triglycerides, and a near-significant tendency towards lower total serum cholesterol levels, compared with non-diabetic controls homozygous for wild-type alleles (Table 3). These results further suggest

Table 1 Clinical and biochemical characteristics of non-diabetic controls and patients with type 2 diabetes. Data are means \pm s.D.

\begin{tabular}{|c|c|c|c|}
\hline & Controls $(n=217)$ & Diabetic patients $(n=145)$ & $P$ value \\
\hline Gender (M/F, \%) & $61.3 / 38.7$ & $60.7 / 39.3$ & $>0.200$ \\
\hline Age (years) & $42.8 \pm 12.3$ & $58.5 \pm 11.0$ & $<0.001$ \\
\hline Body mass index (BMI) $\left(\mathrm{kg} / \mathrm{m}^{2}\right)$ & $25.8 \pm 4.1$ & $30.8 \pm 5.0$ & $<0.001^{\mathrm{a}}$ \\
\hline Waist to hip ratio ${ }^{b}$ & $0.91 \pm 0.06$ & $0.96 \pm 0.06$ & $0.003^{a}$ \\
\hline Systolic blood pressure $(\mathrm{mmHg})$ & $123 \pm 15$ & $141 \pm 22$ & $0.003^{\mathrm{a}}$ \\
\hline Diastolic blood pressure $(\mathrm{mmHg})$ & $77 \pm 12$ & $81 \pm 10$ & $0.024^{\mathrm{a}}$ \\
\hline Total cholesterol $(\mathrm{mmol} / \mathrm{l})$ & $5.25 \pm 0.95$ & $5.15 \pm 1.03$ & $0.143^{\mathrm{a}}$ \\
\hline High-density lipoprotein (HDL)-cholesterol (mmol/l) & $1.47 \pm 0.37$ & $1.27 \pm 0.42$ & $<0.001^{\mathrm{a}}$ \\
\hline Low-density lipoprotein (LDL)-cholesterol (mmol/l) & $3.38 \pm 1.69$ & $2.59 \pm 1.01$ & $<0.001^{a}$ \\
\hline Triglycerides $(\mathrm{mmol} / \mathrm{l})$ & $1.09 \pm 0.66$ & $2.62 \pm 1.61$ & $<0.001^{\mathrm{a}}$ \\
\hline Fasting glucose $(\mathrm{mmol} / /)^{\mathrm{b}}$ & $5.1 \pm 0.5$ & $6.4 \pm 0.8$ & $<0.001^{a}$ \\
\hline Fasting insulin $(\mathrm{pmol} / \mathrm{l})^{\mathrm{b}^{\prime}}$ & $57 \pm 29$ & $107 \pm 72$ & $<0.001^{a}$ \\
\hline
\end{tabular}

\footnotetext{
${ }^{\mathrm{a}} \mathrm{Age}$ was introduced as a covariate for these comparisons. ${ }^{\mathrm{b}}$ These variables were measured only in a subgroup of 145 controls and 20 diabetic patients.
} 
Table 2 Frequencies of the alleles and genotypes of the ACAA-insertion/deletion polymorphism at the $3^{\prime}$ UTR of IGFIIR in non-diabetic controls and patients with type 2 diabetes.

\begin{tabular}{|c|c|c|c|c|}
\hline & Controls & Diabetic patients & $\chi^{2}$ & $P$ value \\
\hline Whole population & $n=217$ (434 alleles) & $n=145$ (290 alleles) & & \\
\hline 144 alleles & $318(73.3 \%)$ & $252(86.9 \%)$ & 19.270 & $<0.001$ \\
\hline 140 alleles & $116(26.7 \%)$ & $38(13.1 \%)$ & & \\
\hline $144 / 144$ & $112(51.6 \%)$ & $112(77.2 \%)$ & 24.255 & $<0.001$ \\
\hline $140 / 144$ & $94(43.3 \%)$ & $29(20.0 \%)$ & & \\
\hline $140 / 140$ & $11(5.1 \%)$ & $4(2.8 \%)$ & & \\
\hline Women & $n=84$ (168 alleles) & $n=57$ (114 alleles) & & \\
\hline 144 alleles & $126(75.0 \%)$ & $98(86.0 \%)$ & 4.998 & 0.025 \\
\hline 140 alleles & $42(25.0 \%)$ & $16(14.0 \%)$ & & \\
\hline $144 / 144$ & $43(51.2 \%)$ & $42(73.7 \%)$ & 7.640 & 0.022 \\
\hline $140 / 144$ & $40(47.6 \%)$ & $14(24.6 \%)$ & & \\
\hline $140 / 140$ & $1(1.2 \%)$ & $1(1.7 \%)$ & & \\
\hline Men & $n=133$ (266 alleles) & $n=88$ (176 alleles $)$ & & \\
\hline 144 alleles & $192(72.2 \%)$ & $155(88.1 \%)$ & 15.845 & $<0.001$ \\
\hline 140 alleles & $74(27.8 \%)$ & $21(11.9 \%)$ & & \\
\hline $144 / 144$ & 69 (51.9\%) & $70(79.5 \%)$ & 17.377 & $<0.001$ \\
\hline $140 / 144$ & $54(40.6 \%)$ & $15(17.1 \%)$ & & \\
\hline $140 / 140$ & $10(7.5 \%)$ & $3(3.4 \%)$ & & \\
\hline \multicolumn{5}{|c|}{ Deviation from Hardy-Weinberg equilibrium considering women and men as a whole } \\
\hline \multicolumn{3}{|c|}{ 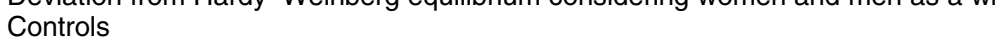 } & 2.435 & 0.733 \\
\hline \multicolumn{3}{|l|}{ Diabetic patients } & 1.497 & 0.872 \\
\hline
\end{tabular}

a functional protective role of the IGFIIR ACAAinsertion/deletion variant against insulin resistance and associated metabolic traits in the non-diabetic population.

\section{Discussion}

In the present study, we have found that the ACAAinsertion/deletion polymorphism at the $3^{\prime}$ UTR of IGFIIR is associated with type 2 diabetes and influences surrogate markers of insulin resistance in non-diabetic subjects.

Diabetic patients showed a decreased frequency of carriers of $140 \mathrm{bp}$ alleles compared with the controls, suggesting a potential protective role of this particular variant against the development of type 2 diabetes. This particular finding was strongly supported by the results of the logistic regression model, in which carrying $140 \mathrm{bp}$ alleles of the ACAA-insertion/deletion polymorphism at the $3^{\prime}$ UTR of IGFIIR was associated with a marked decrease in the risk of having type 2 diabetes, as indicated by the low odds ratio found. Furthermore, the $R^{2}$ of this analysis was considerably high (0.637) indicating that the independent variables included in the model explained a substantial proportion of the risk of having type 2 diabetes in the population studied here.

Moreover, non-diabetic carriers of $140 \mathrm{bp}$ alleles of the ACAA-insertion/deletion polymorphism in IGFIIR presented with decreased fasting insulin and triglyceride levels - which are well-known proxies for

Table 3 Influence of genotypes of the ACAA-insertion/deletion polymorphism at the $3^{\prime}$ UTR of IGFIIR on the clinical and hormonal variables of non-diabetic controls. Data are means \pm S.D.

\begin{tabular}{|c|c|c|c|}
\hline & \multicolumn{3}{|c|}{ IGFIIR genotypes } \\
\hline & $\begin{array}{l}\text { Homozygous for } 144 \text { bp alleles } \\
\qquad(n=112)\end{array}$ & $\begin{array}{l}\text { Carriers of } 140 \text { bp alleles } \\
\quad(n=105)\end{array}$ & $P$ value \\
\hline Gender (M/F, \%) & $(61.6 / 38.4)$ & $(61.0 / 39.0)$ & $>0.200$ \\
\hline Age (years) & $43.5 \pm 12.08$ & $42.1 \pm 12.5$ & $>0.200$ \\
\hline Body mass index $\left(\mathrm{kg} / \mathrm{m}^{2}\right)$ & $25.9 \pm 3.8$ & $25.6 \pm 4.4$ & $>0.200$ \\
\hline Waist to hip ratio ${ }^{a}$ & $0.91 \pm 0.06$ & $0.91 \pm 0.06$ & $>0.200$ \\
\hline Systolic blood pressure $(\mathrm{mmHg})$ & $124 \pm 16$ & $122 \pm 14$ & $>0.200$ \\
\hline Diastolic blood pressure $(\mathrm{mmHg})$ & $78 \pm 12$ & $75 \pm 11$ & 0.138 \\
\hline Total cholesterol $(\mathrm{mmol} / \mathrm{l})$ & $5.38 \pm 1.01$ & $5.10 \pm 0.86$ & 0.069 \\
\hline HDL-cholesterol (mmol/l) & $1.49 \pm 0.39$ & $1.45 \pm 0.35$ & $>0.200$ \\
\hline LDL-cholesterol (mmol/l) & $3.50 \pm 2.18$ & $3.24 \pm 0.85$ & $>0.200$ \\
\hline Triglycerides $(\mathrm{mmol} / \mathrm{l})$ & $1.22 \pm 0.77$ & $0.95 \pm 0.48$ & 0.007 \\
\hline Fasting glucose $(\mathrm{mmol} / \mathrm{l})^{\mathrm{a}}$ & $5.1 \pm 0.5$ & $5.1 \pm 0.5$ & $>0.200$ \\
\hline Fasting insulin $(\mathrm{pmol} / \mathrm{l})^{\mathrm{a}}$ & $62 \pm 29$ & $51 \pm 30$ & 0.037 \\
\hline
\end{tabular}

${ }^{\mathrm{a}}$ These variables were measured only in a subgroup of 145 non-diabetic controls. 
insulin resistance - further suggesting that this variant may play a protective role against insulin resistancerelated traits in the general population.

A limitation of our study is that non-diabetic controls were selected on the basis of normal fasting glucose concentrations, in accordance with the American Diabetes Association criteria (15). However, even assuming that $1.2 \%$ of our controls would have been considered diabetic had an OGTT been performed (20), we actually found an association of the ACAAinsertion/deletion polymorphism at the $3^{\prime}$ UTR of IGFIIR with type 2 diabetes, that might have been stronger if these putative cases of undiagnosed diabetes have been removed from the control population. It seems improbable also that the decreased fasting insulin and triglyceride levels found in non-diabetic carriers of this $140 \mathrm{bp}$ alleles of the ACAA-insertion/deletion polymorphism in IGFIIR could be attributed to a hypothetical $1.2 \%$ of undiagnosed diabetics among them. It should be highlighted that our present findings may also explain the report, in non-diabetic Mexican American individuals of the San Antonio Family Diabetes Study, of linkage of insulin-resistant phenotypes - including fasting insulin - with the marker D6S264, located at 6q25.2-q26 (14). This marker is very close to IGFIIR, located at 6q26 (12), and therefore, our present results provide a convincing explanation for this previously reported evidence of linkage.

The IGFIIR gene encodes a multifunctional receptor that possesses binding sites for mannose-6-phosphate and IGF-II $(21,22)$. The mannose-6-phosphate binding site of this receptor is involved in 25 cellmediated immune functions (11). Tumor suppression (10) and embryonic development (23) are other important functions attributable to the IGFIIR. In conceptual agreement, IGF-II has been shown to affect intrauterine growth (24) as well as pancreatic $\beta$ cell proliferation $(6,7)$. A recent study has suggested that mutations at the $3^{\prime}$ UTR of IGFRII may induce defects in the post-transcriptional process during the synthesis of the IGF-II receptor (25). We hypothesize that the ACAA-insertion/deletion polymorphism at the $3^{\prime}$ UTR of the IGFIIR might be involved in the pathogenesis of type 2 diabetes by its regulatory functions on fetal growth and/or $\beta$ cell proliferation (26). As opposed to the association of the ACAA-insertion/deletion polymorphism at the $3^{\prime}$ UTR of the IGFIIR with type 2 diabetes and insulin-resistant traits described here by us, a previous study (27) showed that an IGFIIR polymorphism located at exon 16, and not the ACAAinsertion/deletion polymorphism at the $3^{\prime}$ UTR, resulted in statistically significant transmission distortion in parent - offspring trios of children with type 1 diabetes. Possibly, this polymorphism influences some of the immune functions mediated by the IGF-II receptor, which has also been identified as a potential target for human autoimmune responses (28).
In conclusion, the ACAA-insertion/deletion polymorphism at the $3^{\prime}$ UTR of IGFIIR is associated with type 2 diabetes in the Spanish population, and influences surrogate markers of insulin resistance in non-diabetic subjects, providing an explanation for the evidence for linkage between insulin-resistant traits and the D6S264 marker at 6q25.2-q26 previously reported in Mexican-Americans.

\section{Acknowledgements}

Supported by grants FIS 02/0741, 05/0341 and 05/0551 to H F E-M, FIS 04/1383, RCMN C03/08, RGTO G03/028, to J M F-R, and RGDM 03/212 to H F E$\mathrm{M}$ and J M F-R, from the Fondo de Investigación Sanitaria, Instituto de Salud Carlos III, Spain, grant GR/SAL/0137/2004 to J L S M, from the Consejería de Educación, Comunidad de Madrid, Spain, and grant BFU2004-03 654 to J M F-R from the Ministerio de Educación y Ciencia, Spain.

\section{References}

1 van Haeften TW \& Twickler TB. Insulin-like growth factors and pancreas beta cells. European Journal of Clinical Investigation 2004 34 249-255.

2 Sandhu MS, Heald AH, Gibson JM, Cruickshank JK, Dunger DB \& Wareham NJ. Circulating concentrations of insulin-like growth factor-I and development of glucose intolerance: a prospective observational study. Lancet 2002359 1740-1745.

3 Nakae J, Kido Y \& Accili D. Distinct and overlapping functions of insulin and IGF-I receptors. Endocrine Reviews 200122 818-835.

4 't Hart LM, Fritsche A, Rietveld I, Dekker JM, Nijpels G, Machicao F, Stumvoll M, van Duijn CM, Haring HU, Heine RJ, Maassen JA \& van Haeften TW. Genetic factors and insulin secretion: gene variants in the IGF genes. Diabetes 200453 S26-S30.

5 Laukkanen O, Pihlajamaki J, Lindstrom J, Eriksson J, Valle TT, Hamalainen $\mathrm{H}$, Ilanne-Parikka $\mathrm{P}$, Keinanen-Kiukaanniemi S, Tuomilehto J, Uusitupa M \& Laakso M. Common polymorphisms in the genes regulating the early insulin signalling pathway: effects on weight change and the conversion from impaired glucose tolerance to Type 2 diabetes. The finnish diabetes prevention study. Diabetologia 200447 871-877.

6 Devedjian JC, George M, Casellas A, Pujol A, Visa J, Pelegrin M, Gros L \& Bosch F. Transgenic mice overexpressing insulin-like growth factor-II in beta cells develop type 2 diabetes. Journal of Clinical Investigation $2000 \mathbf{1 0 5} 731-740$.

7 Serradas P, Goya L, Lacorne M, Gangnerau MN, Ramos S, Alvarez C, Pascual-Leone AM \& Portha B. Fetal insulin-like growth factor-2 production is impaired in the GK rat model of type 2 diabetes. Diabetes $200251392-397$.

8 Gaunt TR, Cooper JA, Miller GJ, Day IN \& O’Dell SD. Positive associations between single nucleotide polymorphisms in the IGF2 gene region and body mass index in adult males. Human Molecular Genetics 200110 1491-1501.

9 San Millan JL, Corton M, Villuendas G, Sancho J, Peral B \& Escobar-Morreale HF. Association of the polycystic ovary syndrome with genomic variants related to insulin resistance, type 2 diabetes mellitus, and obesity. Journal of Clinical Endocrinology and Metabolism 200489 2640-2646.

10 Di Bacco A \& Gill G. The secreted glycoprotein CREG inhibits cell growth dependent on the 5 mannose-6-phosphate/insulin-like growth factor II receptor. Oncogene 200322 5436-5445. 
11 Ikushima H, Munakata Y, Ishii T, Iwata S, Terashima M, Tanaka H, Schlossman SF \& Morimoto C. Internalization of CD26 by mannose 6-phosphate/insulin-like growth factor II receptor contributes to T cell activation. PNAS 200097 8439-8444.

12 Laureys G, Barton DE, Ullrich A \& Francke U. Chromosomal mapping of the gene for the type II insulin-like growth factor receptor/cation-independent mannose 6-phosphate receptor in man and mouse. Genomics 19883 224-229.

13 Riesewijk AM, Xu YQ, Schepens MT, Mariman EM, Polychronakos C, Ropers HH \& Kalscheuer VM. Absence of an obvious molecular imprinting mechanism in a human fetus with monoallelic IGF2R expression. Biochemical and Biophysical Research Communications $1998245272-277$

14 Duggirala R, Blangero J, Almasy L, Arya R, Dyer TD, Williams KL, Leach RJ, O'Connell P \& Stern MP. A major locus for fasting insulin concentrations and insulin resistance on chromosome $6 \mathrm{q}$ with strong pleiotropic effects on obesity-related phenotypes in nondiabetic Mexican Americans. American Journal of Human Genetics 200168 1149-1164.

15 American Diabetes Association. Diagnosis and classification of diabetes mellitus. Diabetes Care 200528 S37-S42.

16 Fernandez-Real JM, Gutierrez C, Ricart W, Castineira MJ, Vendrell J \& Richart C. Plasma levels of the soluble fraction of tumor necrosis factor receptors 1 and 2 are independent determinants of plasma cholesterol and LDL-cholesterol concentrations in healthy subjects. Atherosclerosis $1999146321-327$.

17 Smrzka OW, Fae I, Stoger R, Kurzbauer R, Fischer GF, Henn T, Weith A \& Barlow DP. Conservation of a maternal-specific methylation signal at the human IGF2R locus. Human Molecular Genetics 19954 1945-1952.

18 Lemeshow S, Hosmer DW, Klar J \& Lwanga SK. Adequacy of sample size in health studies. Chichester, UK: World Health Organization, Wiley, 1990.

19 Cohen J. Statistical power analysis for the behavioral sciences. 2nd edn. Hillsdale, NJ: Lawrence Erlbaum, 1988.

20 Harris MI, Eastman RC, Cowie CC, Flegal KM \& Eberhardt MS. Comparison of diabetes diagnostic categories in the US population according to the American Diabetes Association and 1980-1985 World Health Organization diagnostic criteria. Diabetes Care 1997 20 1859-1862.

21 Sleat DE, Chen TL, Raska K, Jr \& Lobel P. Increased levels of glycoproteins containing 10 mannose 6-phosphate in human breast carcinomas. Cancer Research 199555 3424-3430.

22 Killian JK \& Jirtle RL. Genomic structure of the human M6P/IGF2 receptor. Mammalian Genome 199910 74-77.

23 Ludwig T, Eggenschwiler J, Fisher P, D’Ercole AJ, Davenport ML \& Efstratiadis A. Mouse mutants lacking the type 2 IGF receptor (IGF2R) are rescued from perinatal lethality in IGF2 and IGF1R null backgrounds. Developmental Biology 1996177 517-535.

24 Morison IM, Becroft DM, Taniguchi T, Woods CG \& Reeve AE. Somatic overgrowth associated with overexpression of insulin-like growth factor II. Nature Medicine 19962 311-316.

25 Xie S \& Kang JX. Differential expression of the mannose 6-phosphate/insulin-like growth factor-II receptor in human breast cancer cell lines of different invasive potential. Medical Science Monitor 20028 BR293-300.

26 Ong KK \& Dunger DB. Developmental aspects in the pathogenesis of type 2 diabetes. Molecular and Cellular Endocrinology 2001185 145-149.

27 McCann JA, Xu YQ, Frechette R, Guazzarotti L \& Polychronakos C. The insulin-like growth factor-II receptor gene is associated with type 1 diabetes: evidence of a maternal effect. Journal of Clinical Endocrinology and Metabolism 200489 5700-5706.

28 Tarrago D, Aguilera I, Melero J, Wichmann I, Nunez-Roldan A \& Sanchez B. Identification of cation-independent mannose 6-phosphate receptor/insulin-like growth factor type-2 receptor as a novel target of autoantibodies. Immunology $199998652-662$.

Received 22 February 2006

Accepted 24 May 2006 